\title{
Study and modeling of Speed control of Hydraulic Governing System using PD and PID Controllers
}

\author{
Roshni Bhoi ${ }^{1}$, Dr. S.M. Ali ${ }^{2}$ \\ ${ }^{I}$ M.TECH( Power \& Energy System), School of Electrical Engineering, KIIT University, Odisha, India \\ ${ }^{2}$ Professor,School of Electrical Engineering, KIIT University, Odisha, India
}

\begin{abstract}
This paper is based on the speed control of the governing system of a hydraulic turbine system. Governor play an important role in hydraulic turbine as it maintain the stability of the system frequency by controlling the speed of the system. This is done by using two controller Proportional-Derivative controller and Proportional-Integral-Derivative controller. Both the controller have their own way to act to the deviation and response to it. This paper represents designing of speed control models of PD and PID governor and comparing the output of both the models.
\end{abstract}

Keywords: Proportional-Integral-Derivative controller, Proportional-Derivative controller, speed, servosystem

\section{Introduction}

When hydraulic system are consider governing system, turbine generator set become main concern. The speed and frequency become a important factor to be controlled. There are various method to control this speed of turbine. The governing system in hydraulic are specially designed to control the speed of the turbine system. The various governing controller used to govern the speed are; Proportional-Integral controller, Proportional-Derivative controller and Proportional-Integral-Derivative controller. Generally ProportionalIntegral controller are not used anywhere when speed is taken into consideration. PI have a negative effect to the change in speed. I cannot stabilize the system as it cannot detect the deviation. Derivative mode is required to predict the future error. So, Proportional-Derivative controller and Proportional-Integral-Derivative controller are two different controller used in the stabilization of a governing system of a hydraulic system.

\section{Governing System}

The essential part of a hydraulic power unit is a turbine governor which help in efficient conversion to electrical energy of hydraulic mechanical energy. The main challenge of a grid is the load frequency which can be solve by flexible and reliable turbine governing system. PD controller and PID controller are generally used in modeling a speed control governing system.

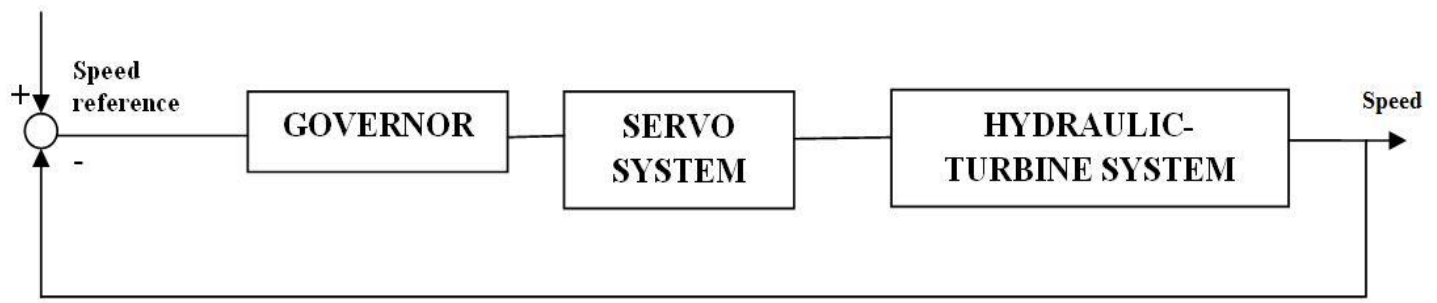

Fig 1: Block diagram for Speed control by hydraulic Governing system

In PD governing used its two mode function to detect the error. The $\mathrm{P}$ mode give an immediate action to the error level in the input by calculating the size of the error. The P mode produces a control action which is proportional to the input error. The $\mathrm{D}$ mode reacts to the input error and produces a control signal to the rate of change and extends the proportionality constant to maintain the stability limits. This mechanism can be accelerated in Proportional-Integral-Derivative controller where an addition I mode which trims the error signal and tries to bring the value to zero. In Fig 2 and Fig 3, transient droop compensator acts as a D mode here which is required for a stable operation when power is affected by the opening and closing of gates in hydraulic turbine. Kdp is the permanent speed droop is the amount of change in output speed in response to the unit change in speed. In hydraulic system this droop used as intermediate feedback which help in calculating the disturbance in the speed. Thus it also help in stabilizing the speed of the system. 


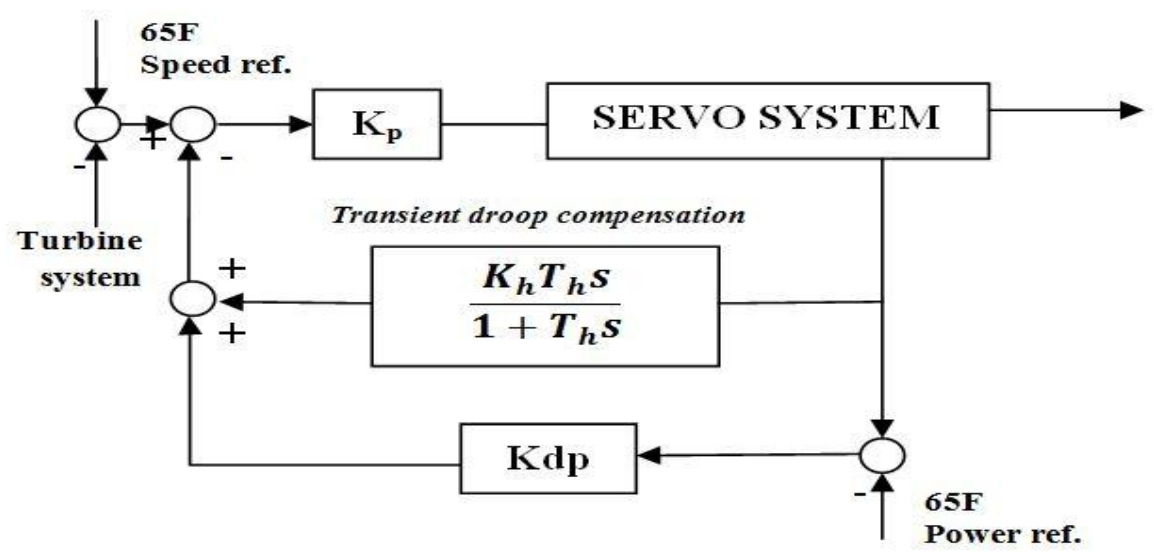

Fig 2: PD Controller Governing System

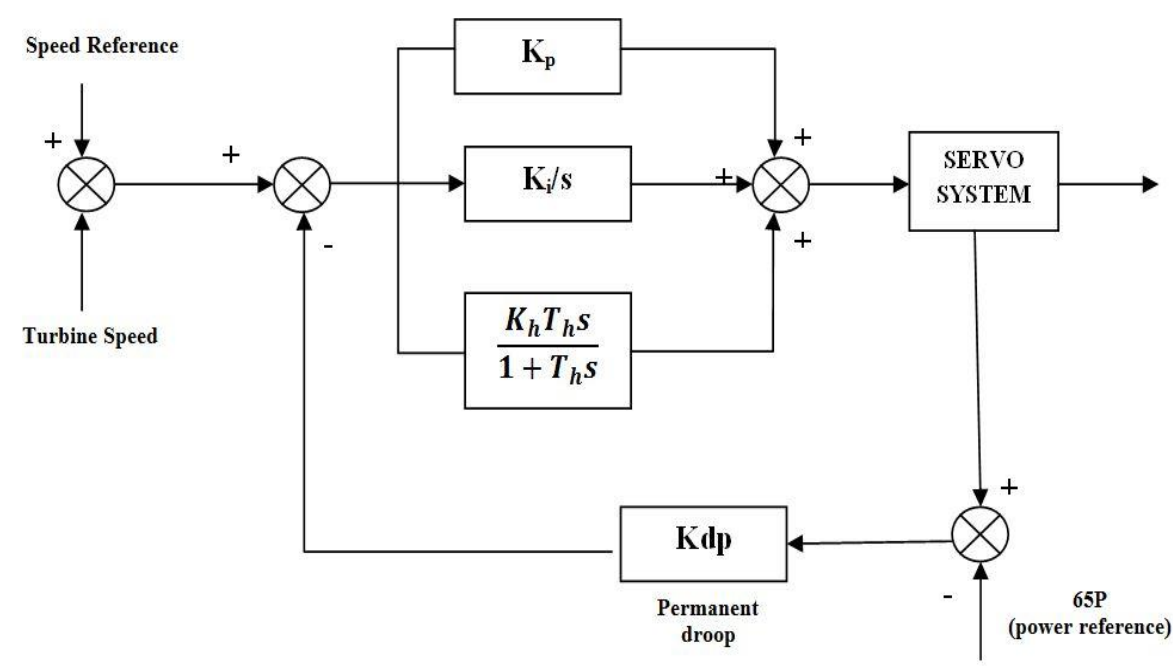

Fig 3: PID Controller Governing System

TABLE 1

Capacity Of The System

\begin{tabular}{|c|c|c|}
\hline Governor & MVA & MW \\
\hline PID & 265.0 & 250 \\
\hline PD & 50.0 & 47.2 \\
\hline
\end{tabular}

TABLE 2

Constant OfPid\&Pd Controller

\begin{tabular}{|c|c|c|c|c|c|}
\hline Governor & $\mathbf{K}_{\mathbf{p}}$ & $\mathbf{K}_{\mathbf{i}}$ & $\mathbf{K}_{\mathbf{h}}$ & $\mathbf{T}_{\mathbf{h}}$ & $\mathbf{K d p}_{\mathbf{p}}$ \\
\hline PID & 6.0 & 10.0 & 0.01 & 0.01 & 0.05 \\
\hline PD & 200.0 & 0.0 & 0.05 & 5.0 & 0.055 \\
\hline
\end{tabular}

\section{Servosystem}

A servosystem main part are: Proportional-Integral-Derivative controller, amplifier, digital to analog convertor, motor and a position sensor. To obtain a smooth and continues operation of load servosystem are used. The output of the governor is feed to the amplifier through the PID controller of the servosystem. The amplified signal are provided to the servomotor by the amplifier through a DAC which act as a filter as well all convertor. The pure signal doesn't affect the motor efficiency. The change in motor position is detected by a position sensor which feedback the deviated value to the input. The controller than takes the necessary action to the error produced. 


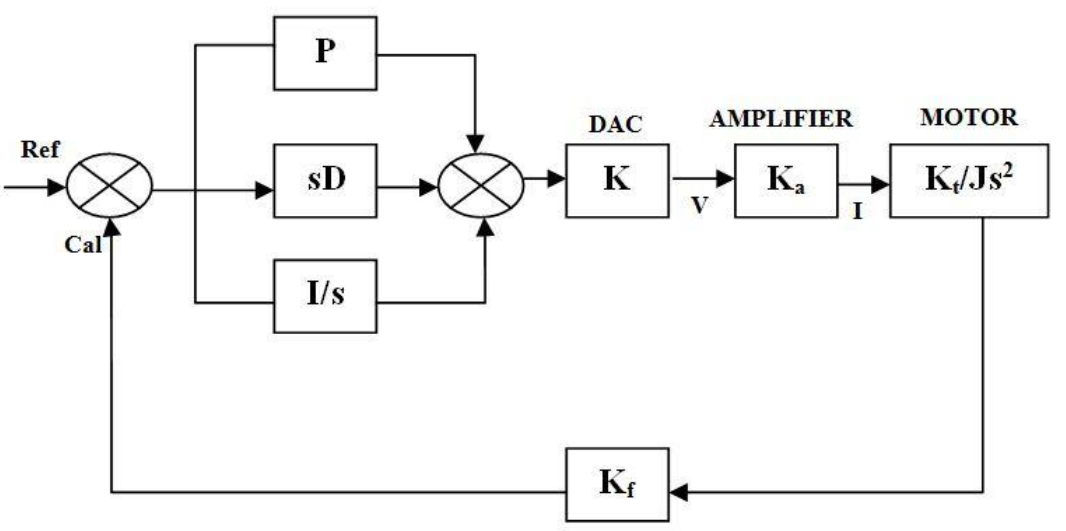

Fig 4: Servosystem

\section{Mathematical Equation}

In PID controller, the transfer function $\mathrm{F}(\mathrm{s})$, related to $x$ number of output to $e$ position error, is,

$F(s)=\frac{x}{e}=P+s D+\frac{I}{s}(1)$

Where,

$\mathrm{P}$ is the proportionality gain of the controller

$\mathrm{D}$ is the derivative gain

$\mathrm{I}$ is the integral gain

Since the servosystem is amplifier mode type, the output current is directly proportional to the input voltage,

$I=K_{a} V(2)$

Then, Torque produced will be,

$T=K_{t} I(3)$

Where, $\mathrm{K}_{\mathrm{a}}$ is the proportionality constant

$\mathrm{K}_{\mathrm{t}}$ is the torque constant

If $\mathrm{J}$ is the moment of inertia of motor and load, the Torque due to opposing friction is neglected, then

$J \alpha=T$

The $\alpha$ is the angular acceleration which can be defined in terms angular displacement $\theta$ as;

$\alpha=\frac{d^{2} \theta}{d^{2} t}$

Taking Laplace of equation (5) and solving for $\theta$ using equation (3) and equation (4);

$\theta=\frac{1}{s^{2}} \frac{K_{t} I}{J}$

Solving equation (6) and equation (2), and including the DAC constant, the servomotor equation can be; $\frac{\theta}{V}=\frac{K K_{a} K_{t}}{J s^{2}}$

TABLE 3

Servosystem Constant

\begin{tabular}{|c|c|c|c|c|c|c|c|}
\hline $\mathrm{K}_{\mathrm{p}}$ & $\mathrm{K}_{\mathrm{d}}$ & $\mathrm{K}_{\mathrm{i}}$ & $\mathrm{K}$ & $\mathrm{K}_{\mathrm{a}}$ & $\mathrm{K}_{\mathrm{t}}$ & $\mathrm{J}$ & $\mathrm{K}_{\mathrm{f}}$ \\
\hline 25 & 0.11 & 1.2 & 0.0488 & 0.5 & 0.1 & 0.0004 & 650 \\
\hline
\end{tabular}

IV. Mathmatical Equation Hydraulic-Turbine Dynamics

Generally, hydraulic turbine equation for change in input torque is written as,

$\Delta U=\frac{K_{1}+K_{2} T_{W} S}{1+K_{5} T_{w} S} \Delta Y+\frac{K_{3}+K_{4} T_{w} S}{1+K_{5} T_{w} S} \Delta N$

The coefficients $K_{1}$ to $K_{5}$ are the constant which are defined in equation (8).

$K_{1}=\frac{\partial U}{\partial Y}$

$K_{2}=\left(\frac{Q}{2 H}-\frac{N}{2 H} \frac{\partial Q}{\partial N}\right) \frac{\partial U}{\partial Y}+\left(\frac{N}{2 H} \frac{\partial U}{\partial N}-\frac{U}{H}\right) \frac{\partial Q}{\partial Y}$

$K_{3}=\frac{\partial U}{\partial N}$

$K_{4}=\frac{Q}{2 H} \frac{\partial U}{\partial N}-\frac{U}{H} \frac{\partial Q}{\partial N}$

$K_{5}=\frac{Q}{2 H}-\frac{N}{2 H} \frac{\partial Q}{\partial N}$

Where, $\mathrm{Q}$ is the discharge

$\mathrm{N}$ is the turbine speed

$\mathrm{H}$ is the turbine head 
$\mathrm{Y}$ is the gate position

$\mathrm{U}$ is the torque

Here, $\mathrm{T}_{\mathrm{w}}$ is the water inertia time constant, which can be defines as,

$T_{w}=\frac{Q_{n}}{g H_{n}} \frac{L}{A}$

Where, $\mathrm{Q}_{\mathrm{n}}$ is the rated discharge

$\mathrm{H}_{\mathrm{n}}$ is the rated head at the entrance of turbine

$\mathrm{L}$ is the length of the penstock

$\mathrm{A}$ is the cross section area of the penstock

$\mathrm{g}$ is the acceleration due to gravity

The turbine model can be represented in terms of $\Delta \mathrm{T}$ input torque and $\Delta \mathrm{N}$ speed,

$\Delta N=\frac{\Delta U}{T_{m} s}$

$\mathrm{T}_{\mathrm{m}}$ is called as mechanical starting constant time, which is defined as,

$T_{m}=\frac{\pi G D^{2} N^{2}}{120 g U_{n}}$

Where, $\mathrm{U}_{\mathrm{n}}$ is the torque at rated speed

$\mathrm{GD}^{2}$ is the flywheel effect is defined as,

$G D^{2}=\frac{1800 P T}{\epsilon N^{2}} k N m^{2}$

Where, $\mathrm{P}$ is the power at its rated value

$\mathrm{T}$ is the wicket gate's time closure

$\epsilon=\frac{\Delta N}{N}$

$\varepsilon$ is the coefficient for the incremental permissible speed which is,

V. Results And Discussion

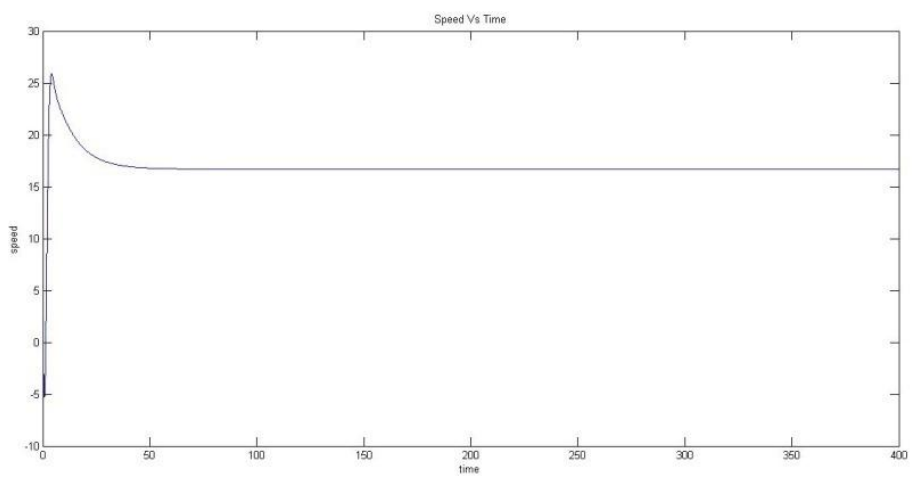

Fig 5: Speed Vs Time curve of the servosystem of the PID Governing System

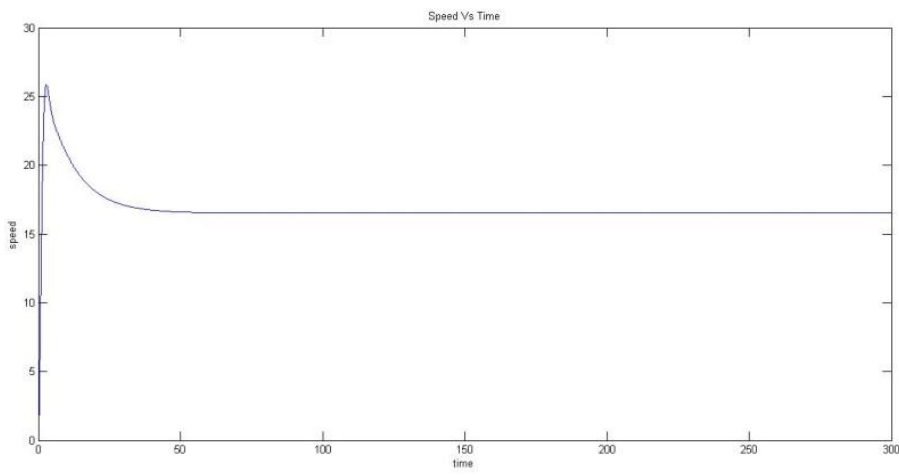

Fig 6: Speed Vs Time curve of the servosystem of PD Governing System

In fig 5 and fig 6, there is a sudden increase in speed within a short period of time. The PID controller after receiving the deviated signal response to the sudden rise of speed and try to normalizes the value. Then the speed become constant after the servosystem reacts to the variation. The reaction to the variation is quicker in fig 5 than in fig 6 this is due to the presence of PID controller in both governing and servosystem. 


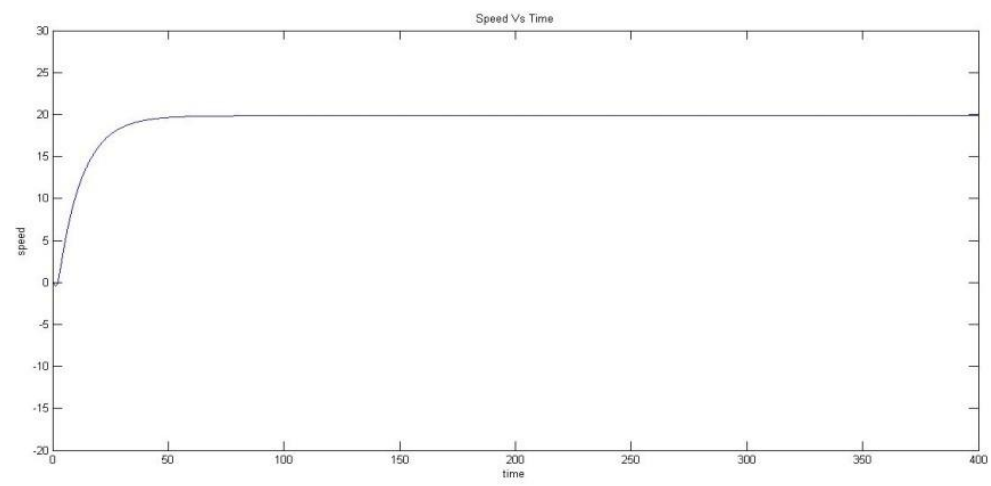

Fig 7: Speed Curve for the PID Governing System

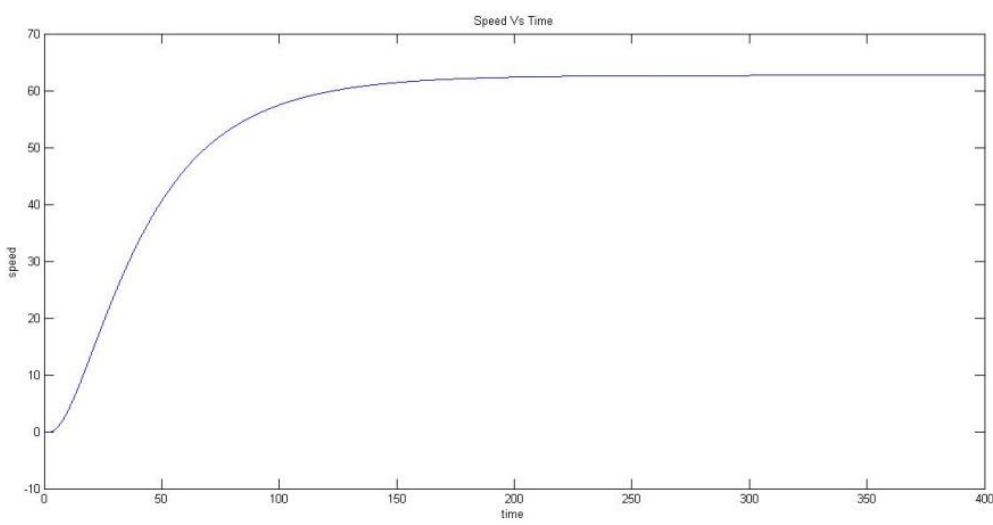

Fig 8: Speed Curve for the PD Governing System

In fig 7 and fig 8 , the speed curve increases exponentially with respect to time. In both graph the settling time is obtained thereby bringing the speed to constant and maintain the system frequency constant. In fig 8 the settling time is 150 secs more than the fig 7 setting time i.e. near to 80 secs. This is due to lack of addition I mode in PD governing system. The PID controller have a fast stabilizing ability than the governor with PD controller.

\section{Conclusion}

Both Proportional-Derivative controller Proportional-Integral-Derivative controller have better response to the variation and help in stabilizing the change in load in hydraulic system. Though ProportionalDerivative controller are slow they are used in the hydro plant where speed variation is minimum like in large hydro power plant. The plant where the water speed is high Proportional-Integral-Derivative controller are implemented since there is more chance of losses.

\section{References}

[1]. 'Practical hydraulic turbine Model.' ,by Atsushi Izena, HidemiKihara, Toshikazu Shimujo, Kaiichirou Hirayama, Nobuhiko Furukawa, TakahisaKAgaeyama, Takashi Goto, IEEE Conference on, 2006

[2]. 'Hydraulic turbine and turbine control models for system dynamic studies', by IEEE Committee report, IEEE Trans. On Power Systems, 7(1), p: 167-179, 1992

[3]. 'Design of Micro Hydel Power Plant' by Vineesh V, A. Immanuel Selvakumar, IJEAT, Vol. 2, issue 2, pp. 136-140, December 2012

[4]. 'Generation of Electrical Energy', by Dr. B. R Gupta, Sixth Edition, ISBN : 81-219-0102-2, by Eurasia Publishing House

[5]. 'Hydro turbine model for system dynamic studies', by E DE Jaeger, N. Janssens, B. Malfliet and F. Van De Meulebroeke, IEEE Transacations on Power Systems, 9(4), 1999

[6]. 'Control systems Engineering' by I.J Nagrath, M.Gopal, Fifth Edition, ISBN(13):978-81-224-2008-1, ISBN(10): 81-224-2008-7, by New Age International Publishers.

[7]. 'Hydraulic transient guidelines for protecting water distribution systems,'Boulos, Vol.97. 2005. Denver, Co, ETATS-UNIS: American water works Association. 14

[8]. 'Dynamic Model of a Small Hydropower Plant' by C.Jaliu, I. Visa, D. Diaconescu, R. Saulescu, M. Neagoe, IEEE trans. Pp: 12171223, Optimization of Electrical and Electronic Equipment, 2010

[9]. 'Stability of a Pump storage hydro-power station connected to a power system', S.P Mansoor, D.I. Jones, D.A. Bradley, F.C. Aris\& G.R. Jones ,Power Engineering Society 1999 Winter Meeting, IEEE, Vol.1, p: 646-650, 31 Jan-4 Feb, 1999

[10]. 'Hydro turbine and Governor Modelling', by L . A Lucero Tenorio, Norwegian University Science \& Technology, 2010 